\title{
FAST FY 2018 Data Call: A Preliminary Review
}

\author{
Ron Stewart
}

March 2019

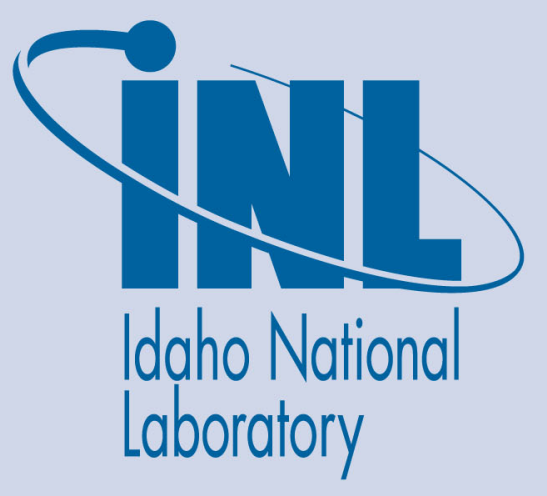

The INL is a U.S. Department of Energy National Laboratory operated by Battelle Energy Alliance 


\title{
FAST FY 2018 Data Call: A Preliminary Review
}

\author{
Ron Stewart
}

March 2019

\section{Idaho National Laboratory Idaho Falls, Idaho 83415}

http://www.inl.gov

Prepared for the U.S. Department of Energy

Office of Energy Efficiency and Renewable Energy, Office of Nuclear Energy Under DOE Idaho Operations Office

Contract DE-AC07-05ID14517, DE-AC07-05ID14517 


\section{FAST FY 2018 Data Call: A Preliminary Review}

\section{INTERFUEL - March 2019}

Ron Stewart

FAST Team Lead

Idaho National Laboratory 


\section{Topics}

- Status of FY 2018 fleet data submission

- Overview of the fleet

- This year's review process 


\section{Status of FY 2018 Submission}

- All reporting agencies submitted vehicle-level data for FY 2018

- 40 of 50 reported VLD in FY 2017

- 48 reporting agencies

- 3 agencies finishing review \& corrections

- All other agencies' submissions considered final

- Caveat: All data shown here is preliminary!

- Current as of 2019-03-06

- Will change before considered final 


\section{Overview of FY 2018 Fleet Data}

\section{Federal Vehicle Inventory}

Inventory by Fiscal Year and Ownership

$\square \mathrm{CL} \square \mathrm{GL} \square \mathrm{AO}$
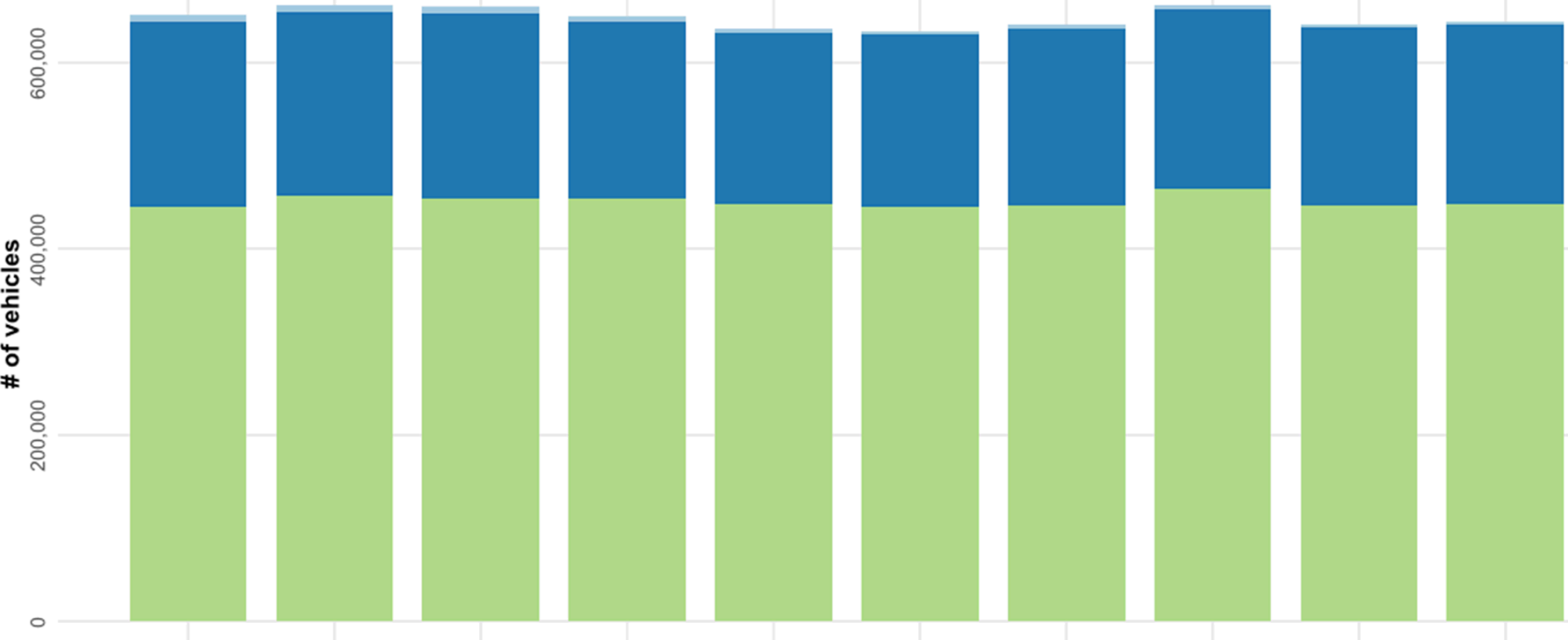

2009

2010

2011

2012

2013

Fiscal Year

2015

2016

2017

2018 


\section{Overview of FY 2018 Fleet Data}

\section{Federal Vehicle Inventory}

$\%$ Inventory by Fiscal Year and Vehicle Class

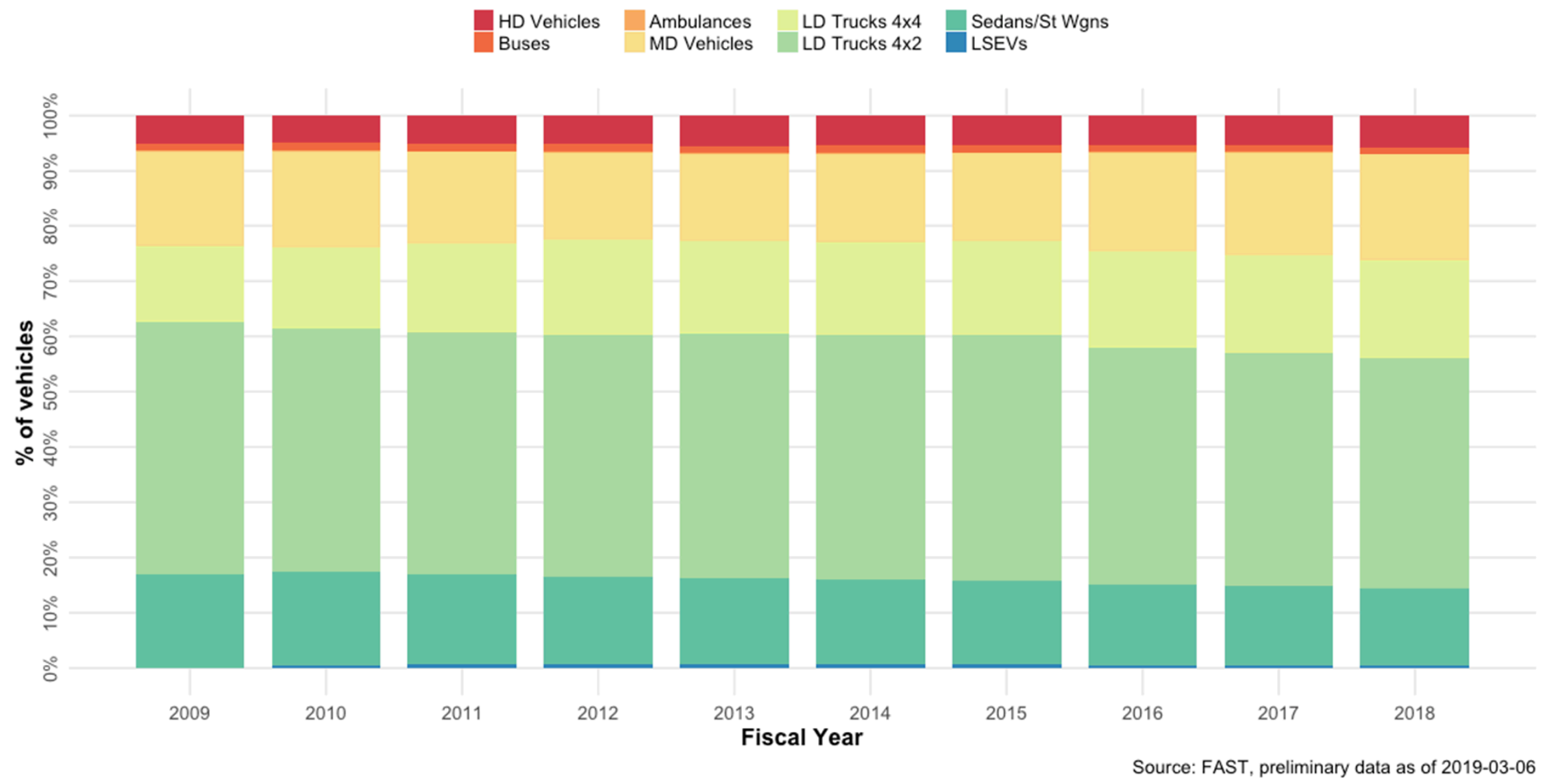




\section{Overview of FY 2018 Fleet Data}

\section{Federal Vehicle Inventory (excluding USPS)}

$\%$ Inventory by Fiscal Year and Vehicle Class

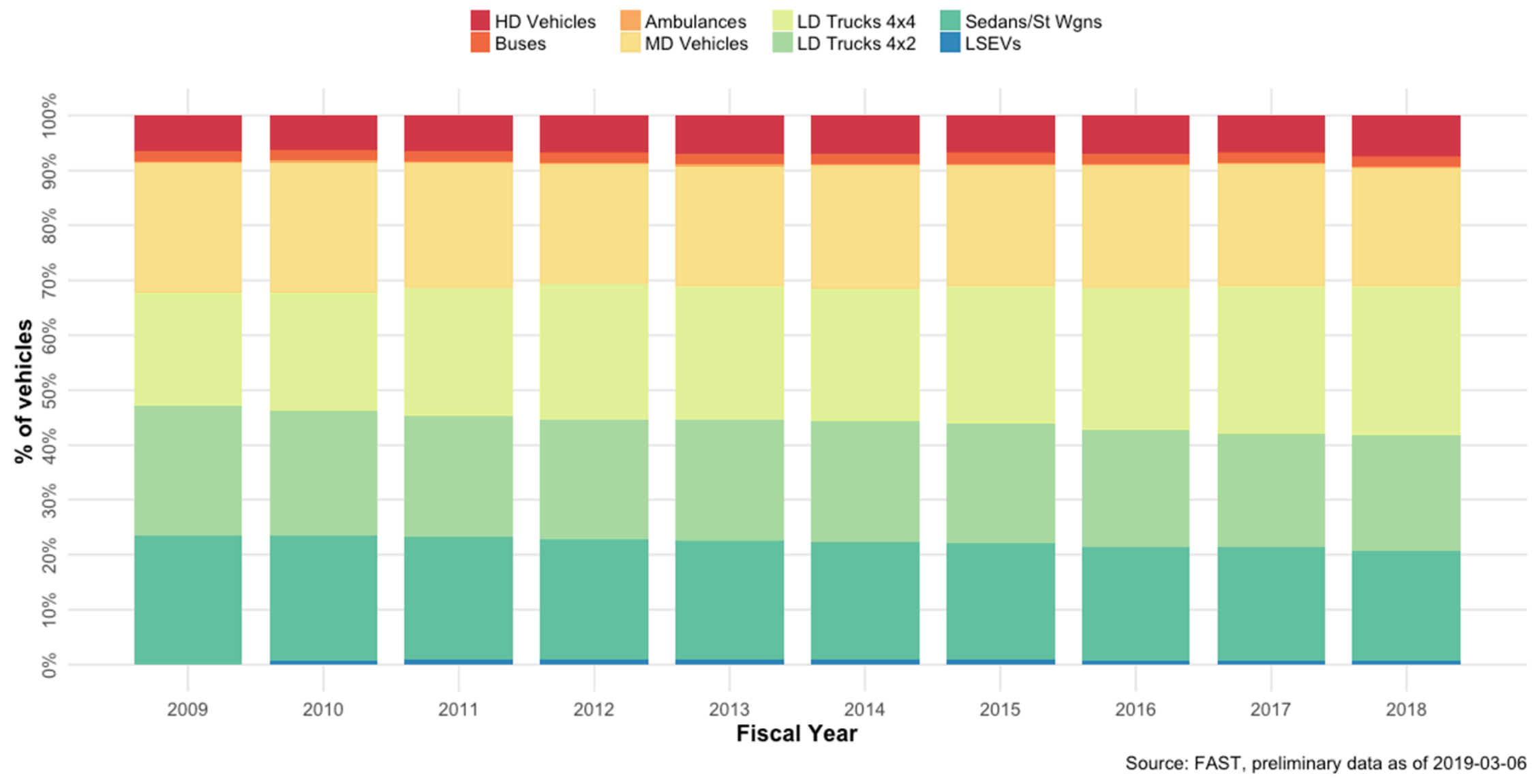




\section{Overview of FY 2018 Fleet Data}

\section{Federal Vehicle Acquisitions}

FY 2018 Acquisitions by Vehicle Class

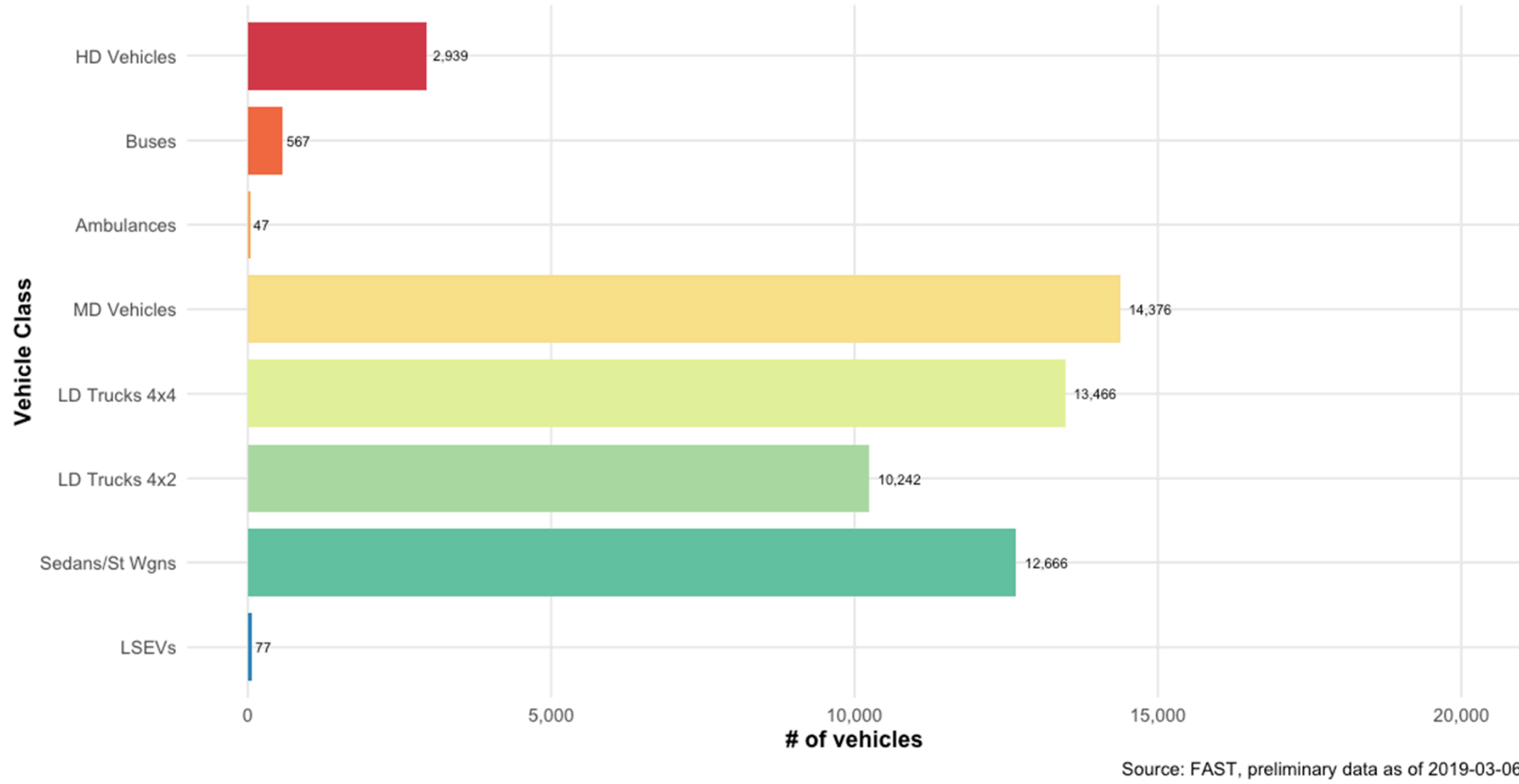




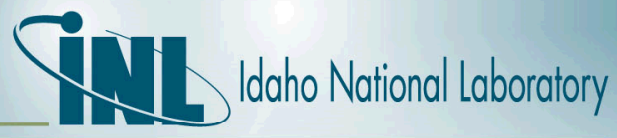

\section{Overview of FY 2018 Fleet Data}

\section{Federal Vehicle Disposals}

FY 2018 Disposals by Vehicle Class

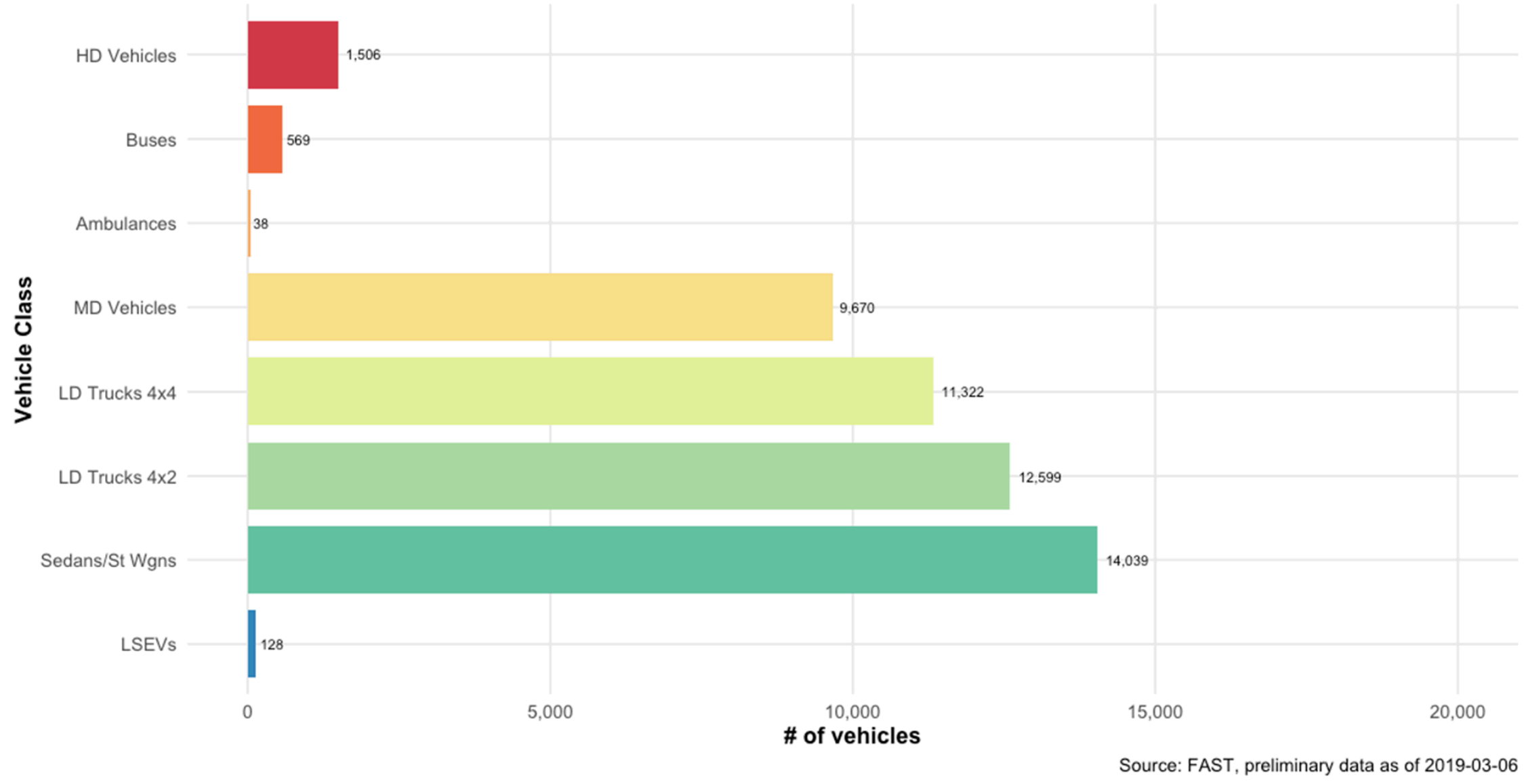




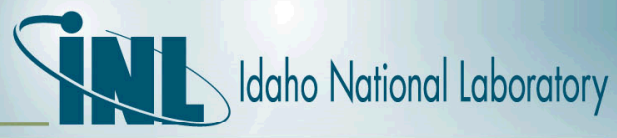

\section{Overview of FY 2018 Fleet Data}

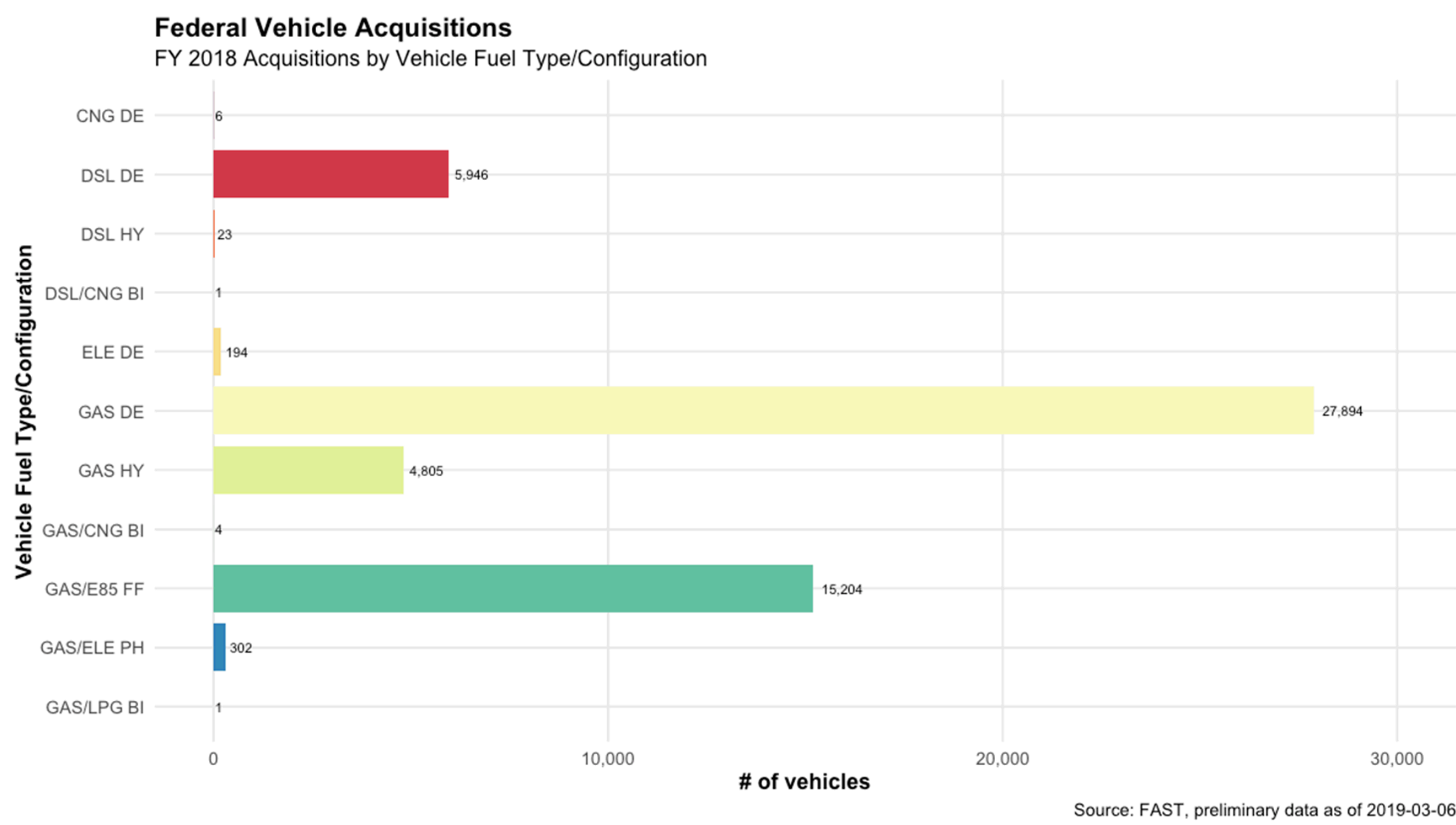




\section{Overview of FY 2018 Fleet Data}

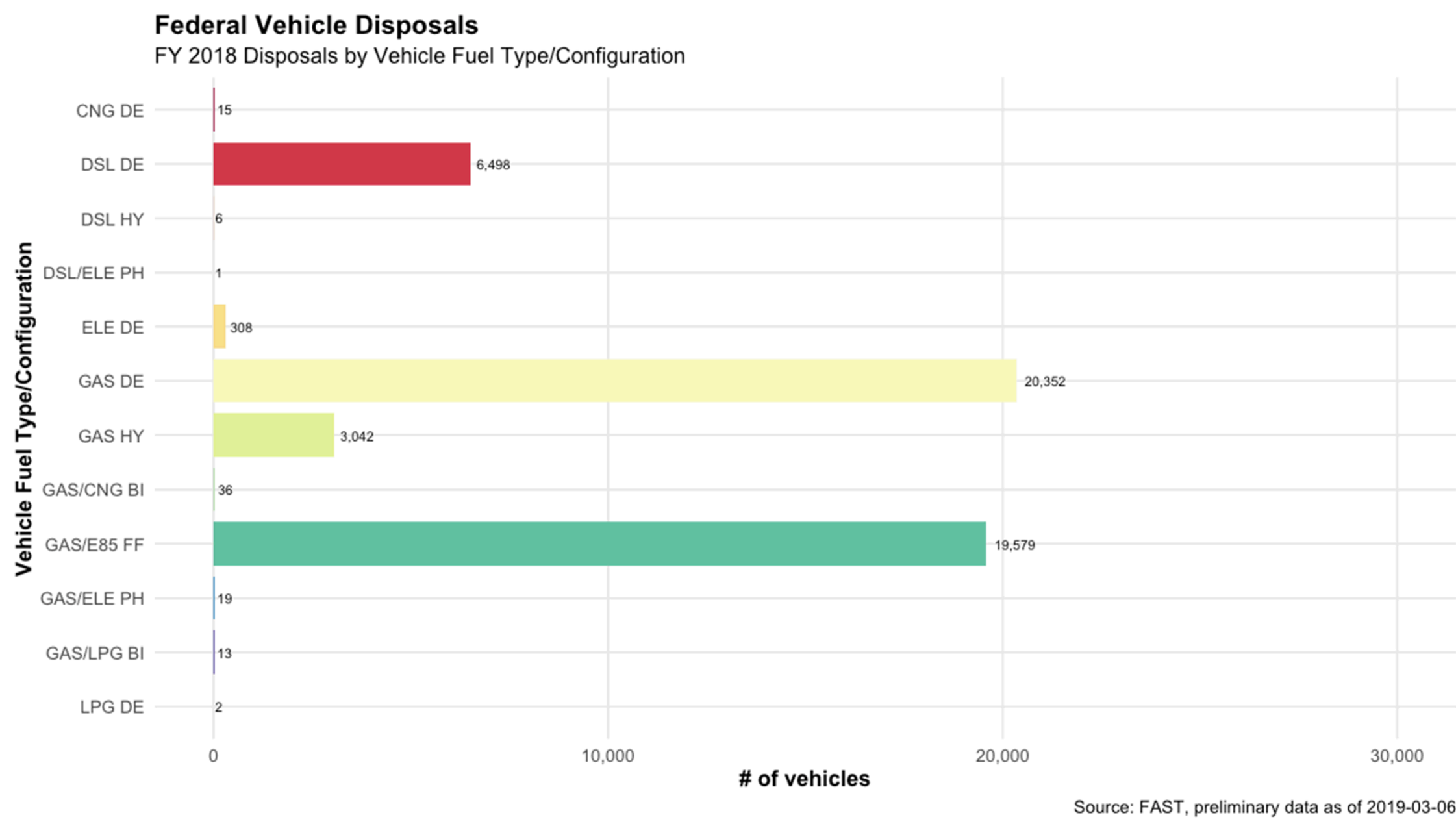




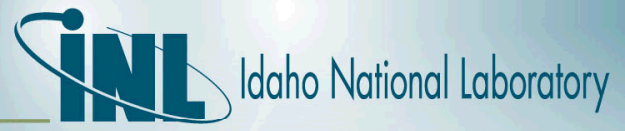

\section{Overview of FY 2018 Fleet Data}

\section{Federal Vehicle Inventory}

Inventory by Model Year

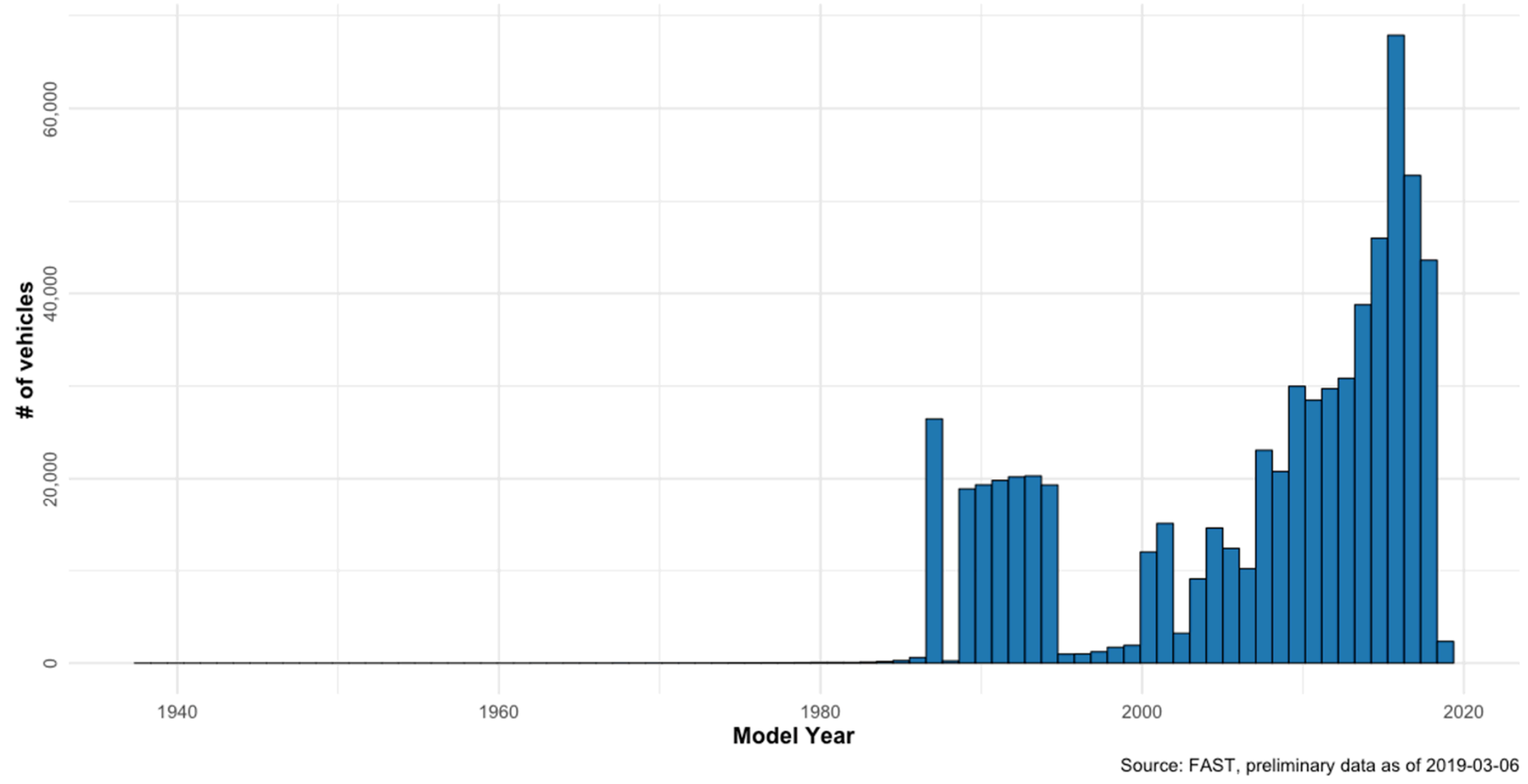




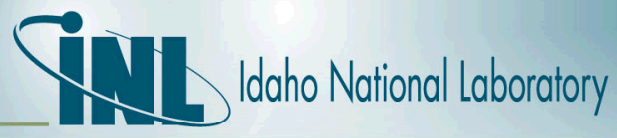

\section{Overview of FY 2018 Fleet Data}

\section{Federal Vehicle Acquisitions and Disposals}

Acquisitions and Disposals by Model Year

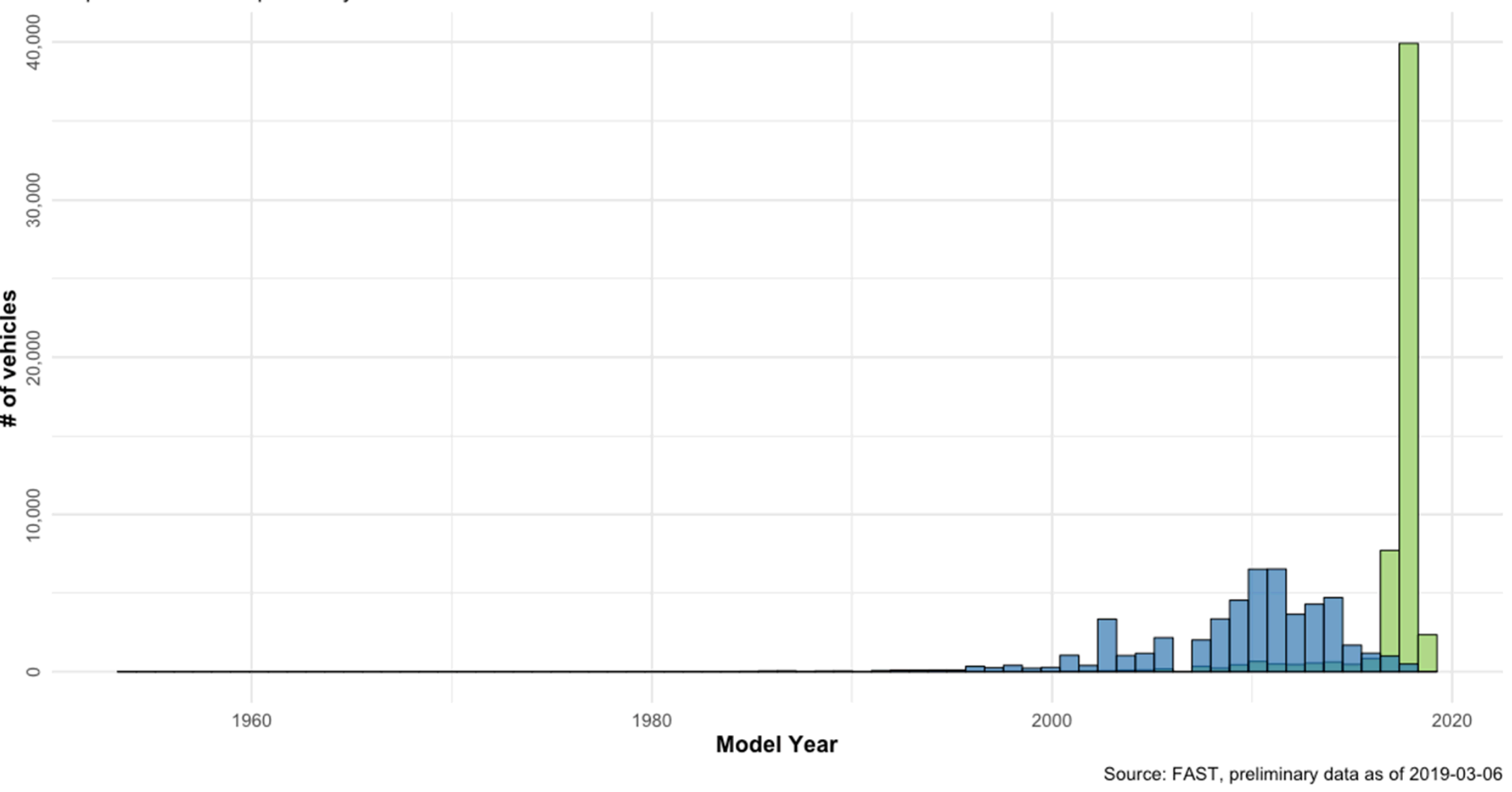




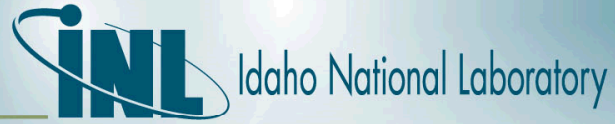

\section{Overview of FY 2018 Fleet Data}

Federal Vehicle Miles

Miles by Fiscal Year

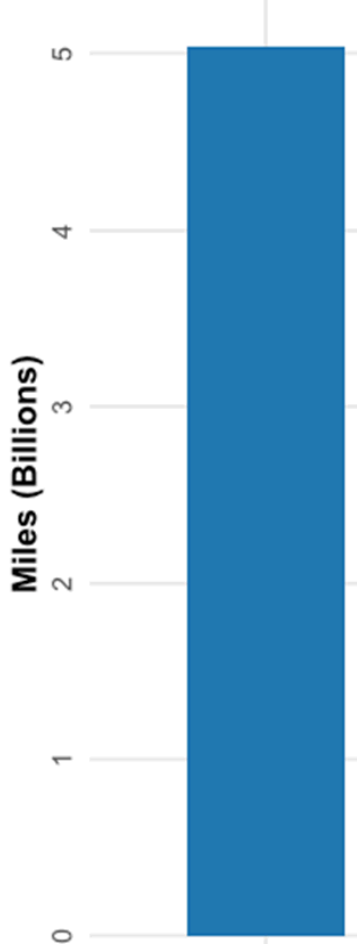

2009

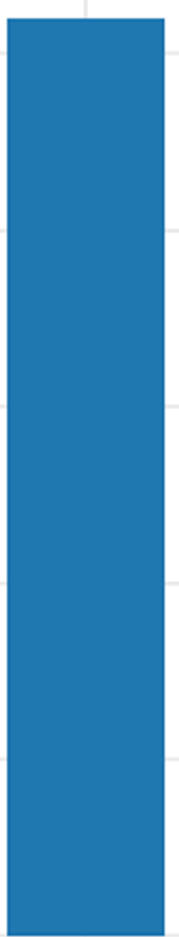

2010

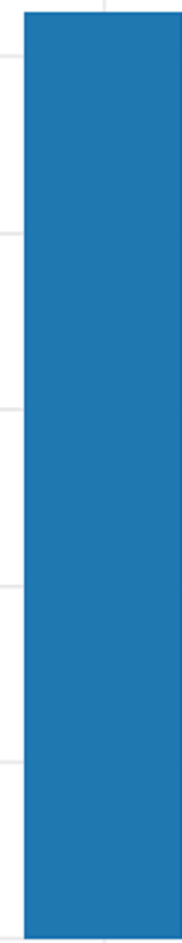

2011

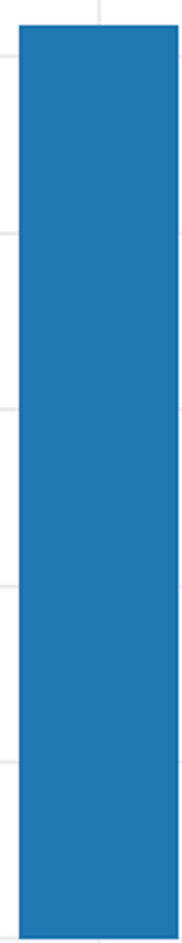

2012

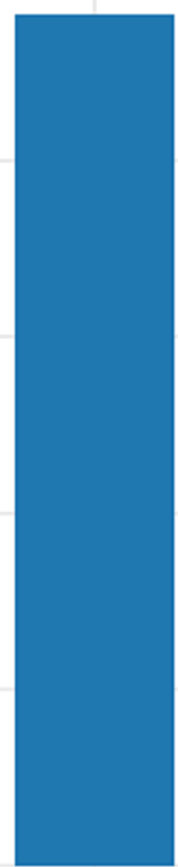

2013

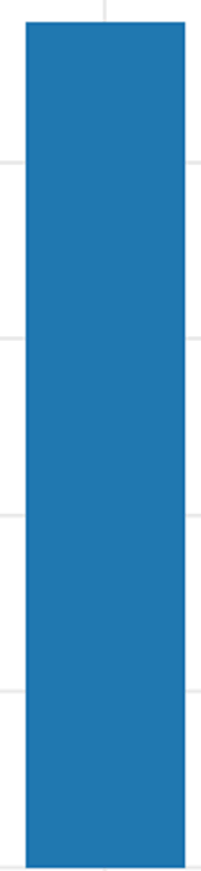

2015

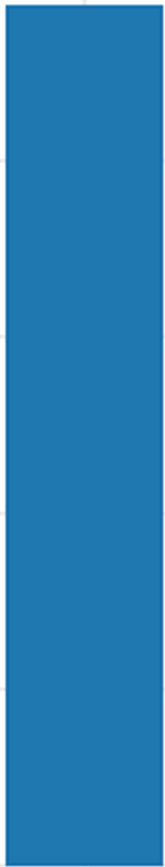

2016

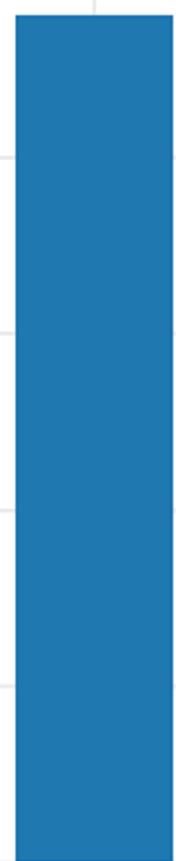

2017

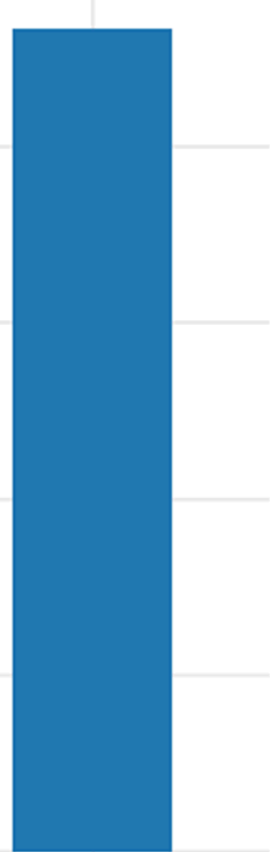

2018

Source: FAST, preliminary data as of 2019-03-06 


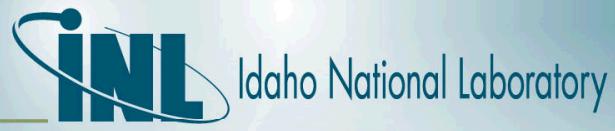

\section{Overview of FY 2018 Fleet Data}

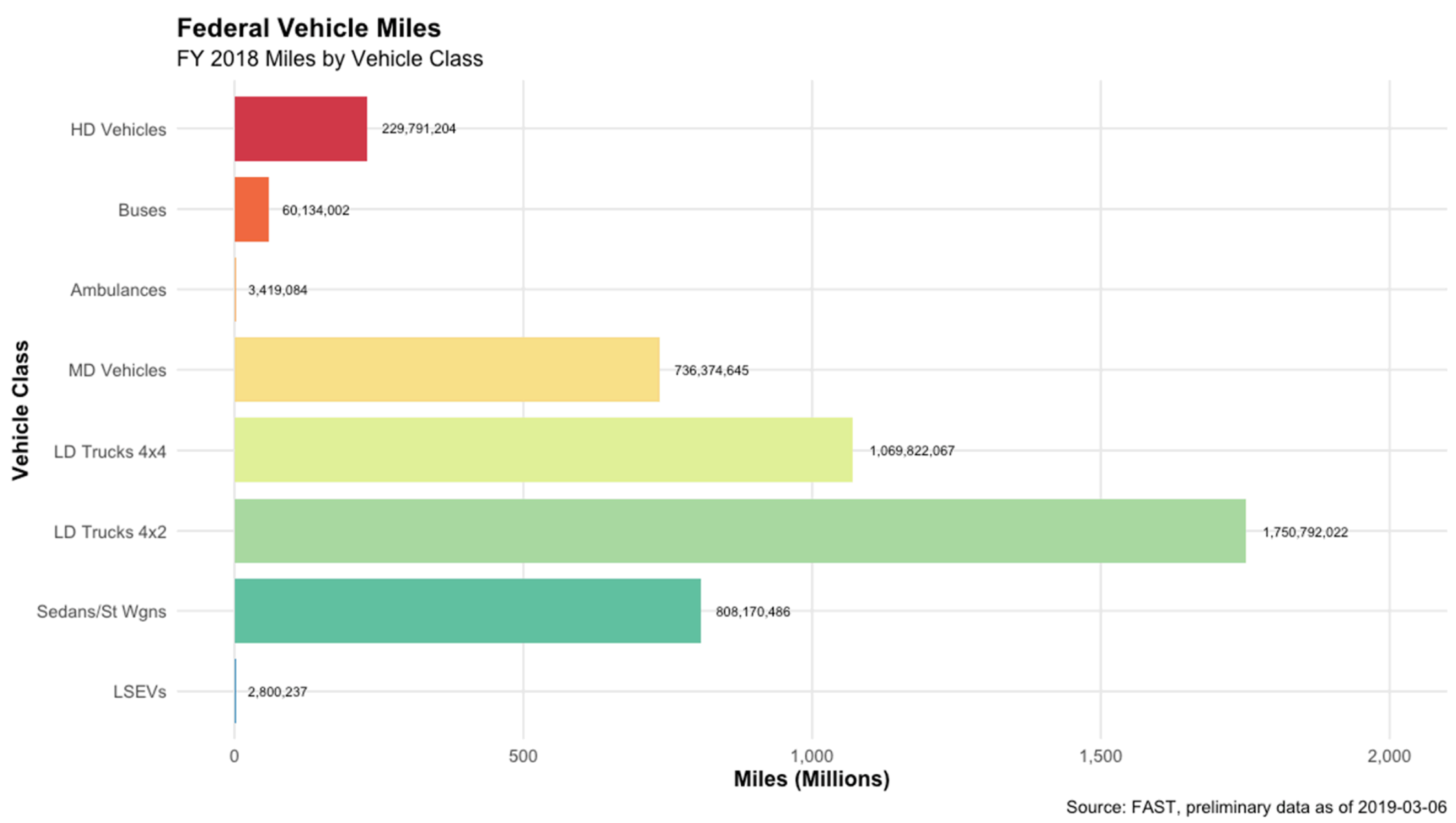




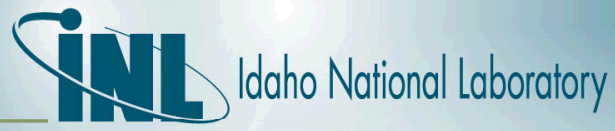

\section{Overview of FY 2018 Fleet Data}

Federal Vehicle Miles (excluding USPS)

FY 2018 Miles by Vehicle Class

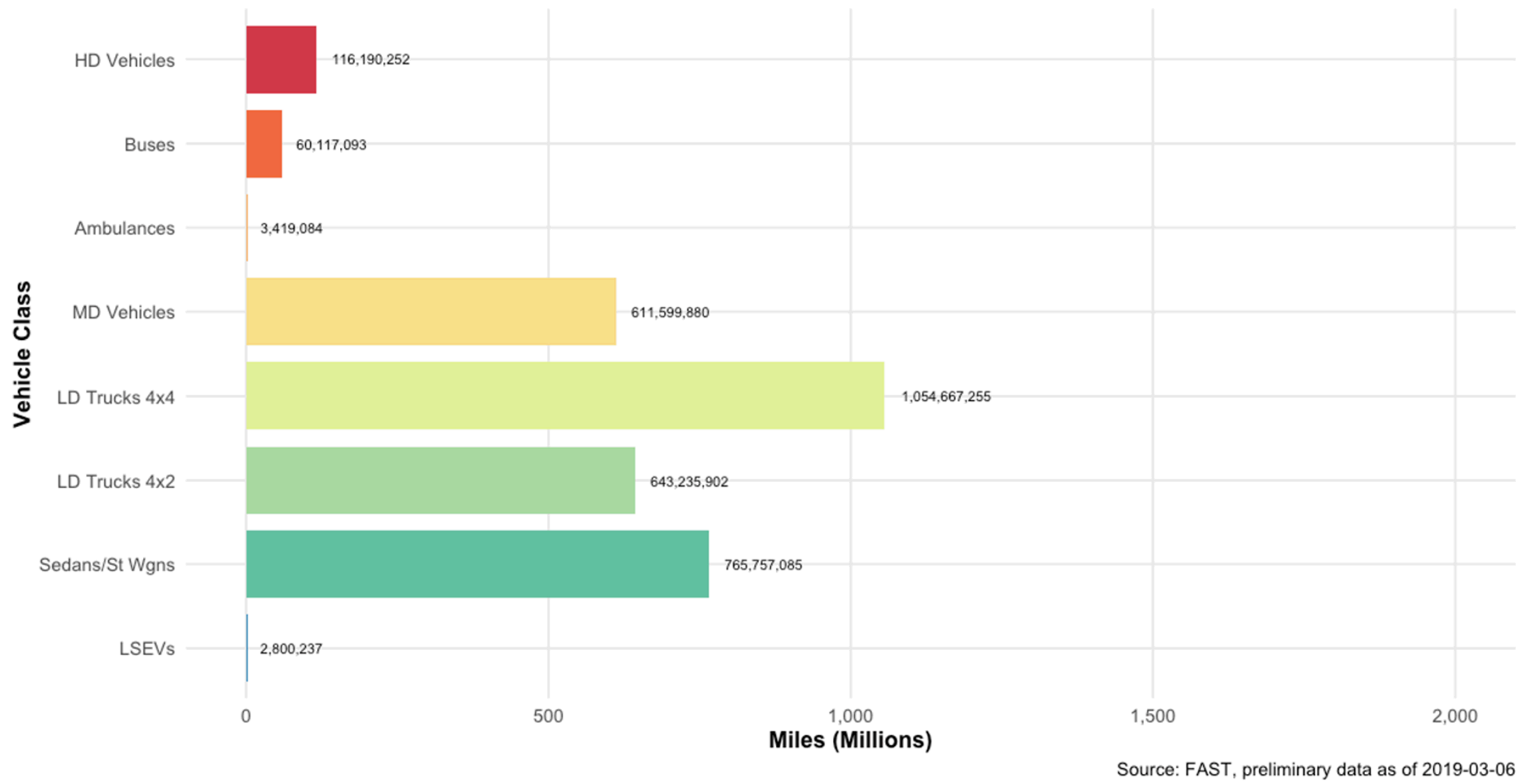




\section{Overview of FY 2018 Fleet Data}

\section{Federal Vehicle Fuel Consumption}

Fuel Consumption by Fiscal Year and Fuel Type

\begin{tabular}{l|l|l|l|l|l}
\hline HYD & LNG & CNG & B100 & E85 & GAS \\
\hline ELE & LPG & R100 & B20 & DSL &
\end{tabular}

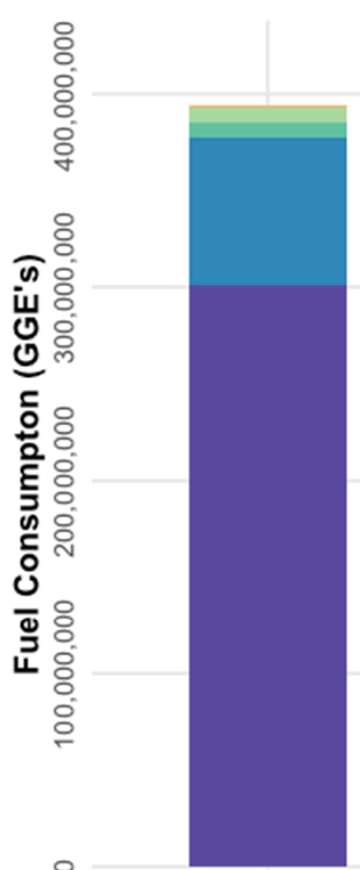

2009

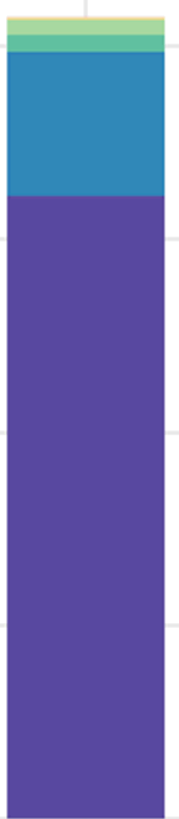

2010

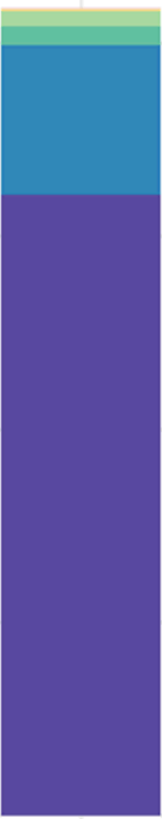

2011

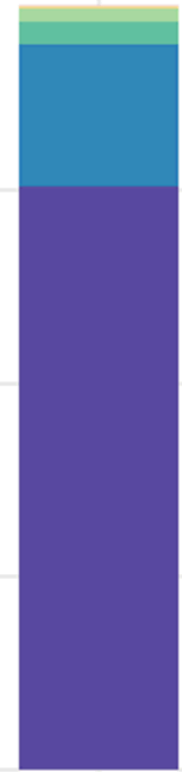

2012

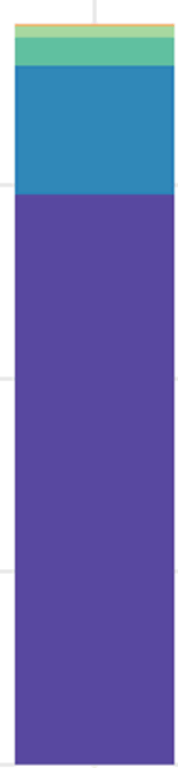

2013

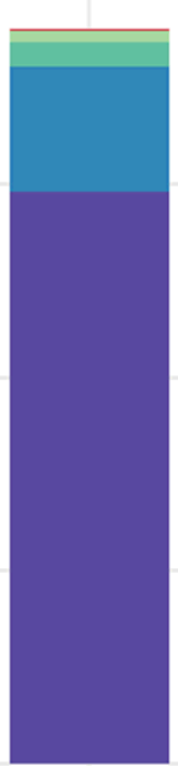

2014 Fiscal Year

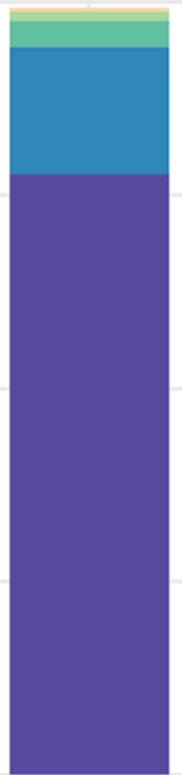

2015

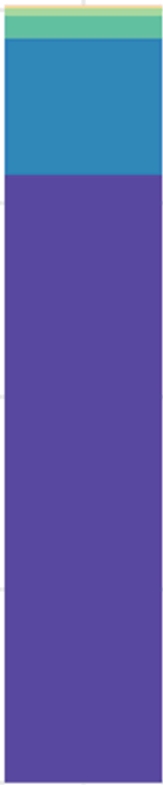

2016

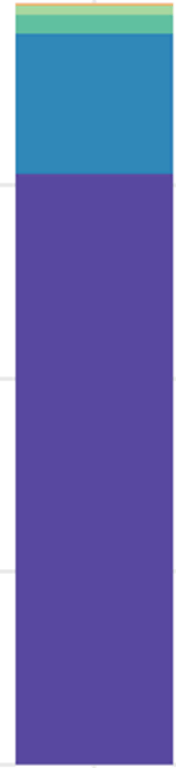

2017

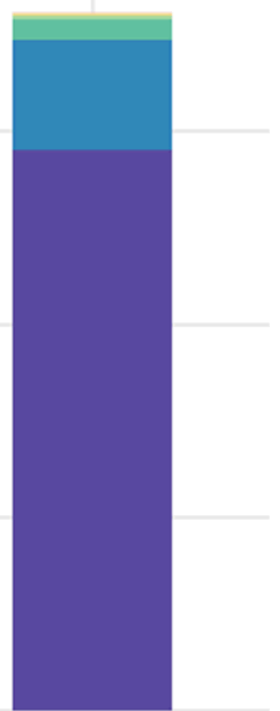

2018 


\section{Overview of FY 2018 Fleet Data}

\section{Federal Vehicle Fuel Consumption}

$\%$ Fuel Consumption by Fiscal Year and Fuel Type

\begin{tabular}{l|l|l|l|l|l}
\hline HYD & LNG & CNG & B100 & E85 & GAS \\
ELE & LPG & R100 & B20 & DSL &
\end{tabular}
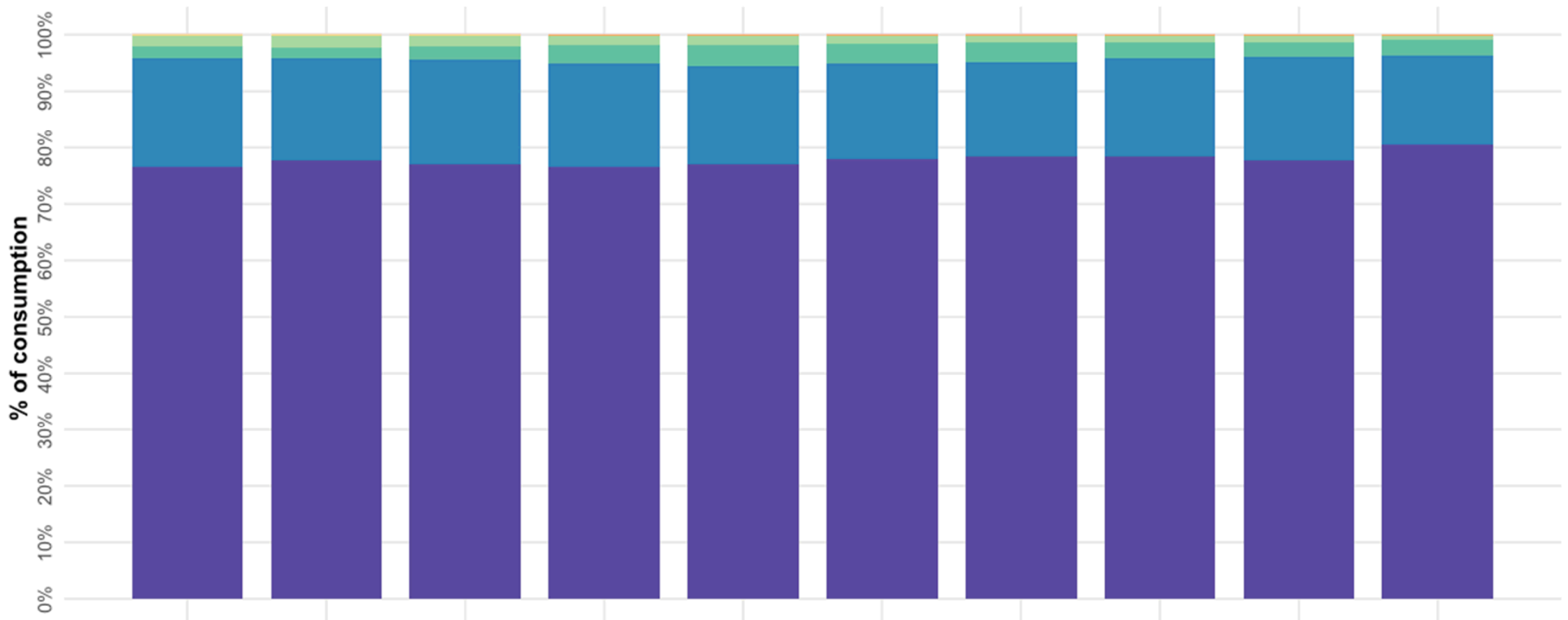

2009

2010

2011

2012

2013

2014

2015 Fiscal Year

2017

2018 


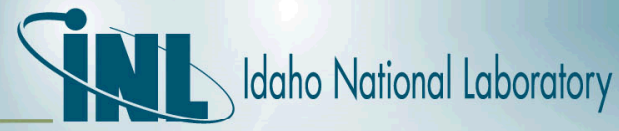

\section{Overview of FY 2018 Fleet Data}

\section{Federal Vehicle Fuel Consumption}

FY 2018 Fuel Consumption by Fuel Type

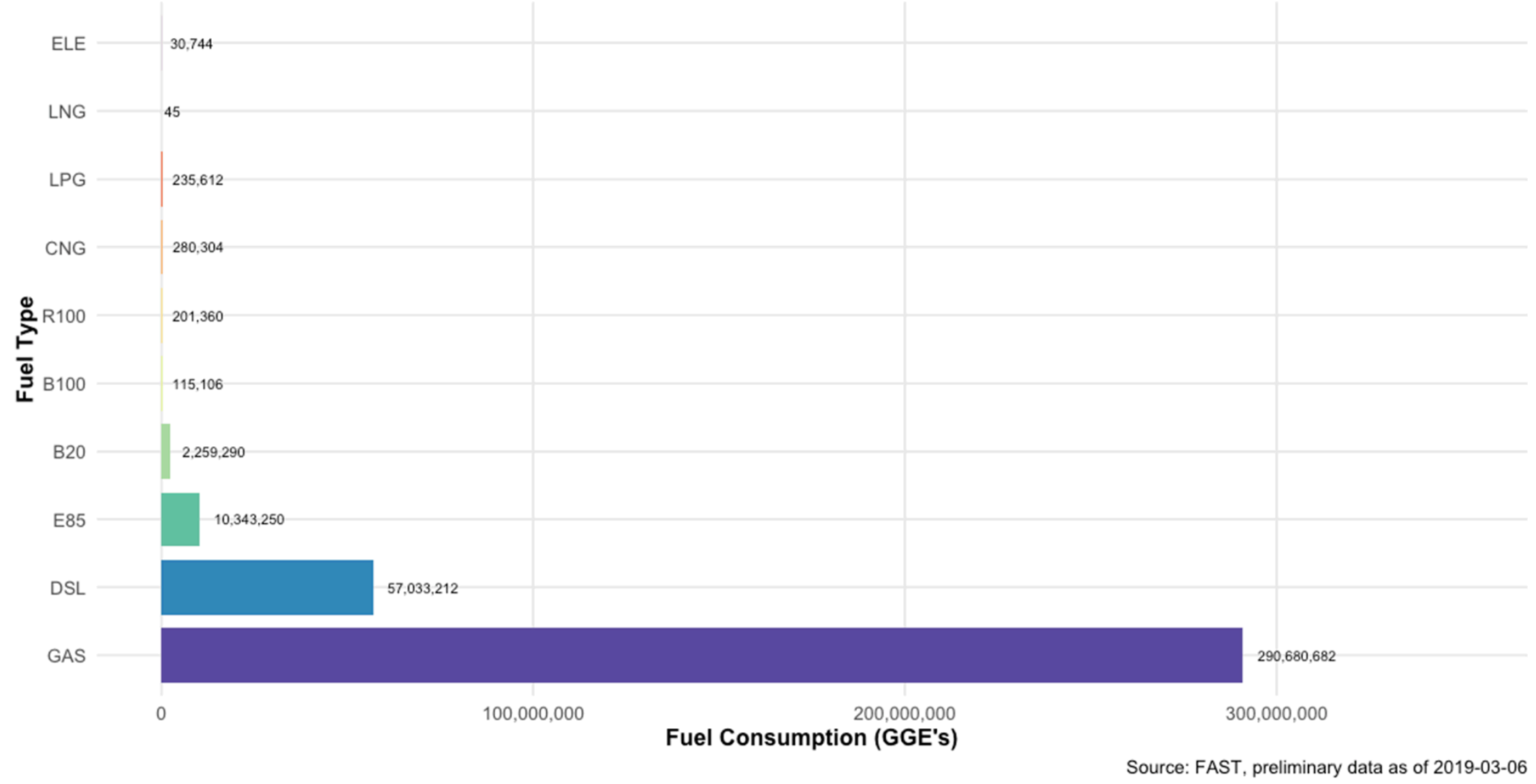




\section{New Review Process}

- With recent move to VLD, significant external interest in fleet data - "How good is the data?"

- New review process implemented this year

- Identify potential issues in agency submissions

- Communicate those to reporting agency

- Agency reviews and responds

- Corrects, where feasible

- Assemble and summarize review/response/corrections

- FAST management team has basis for...

- Answering that "How good is it?" question

- Tracking improvement in future years 


\section{New Review Process: Dashboard}

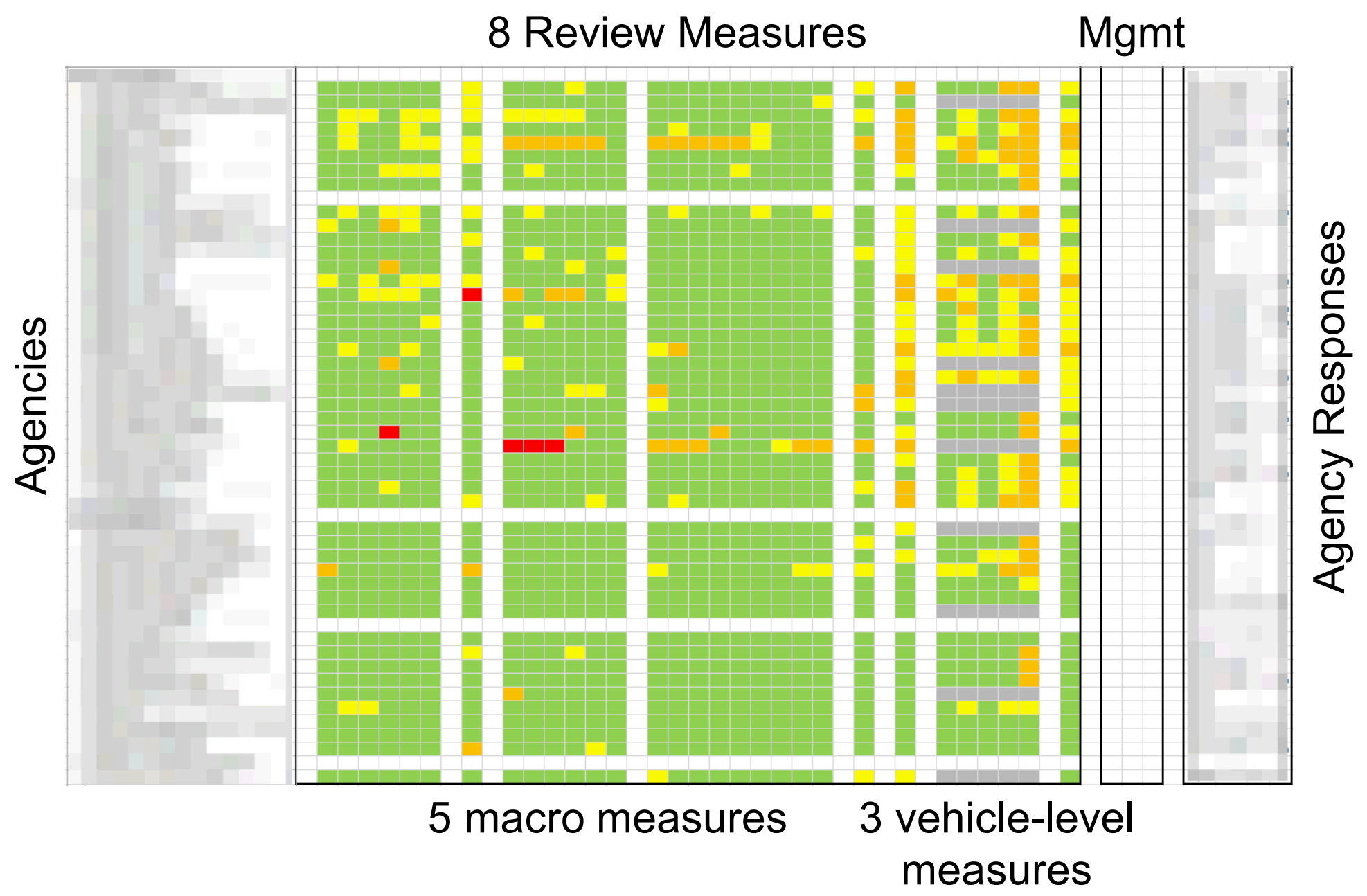




\section{New Review Process: Areas of Concern}

- Incomplete response to review feedback

- Changing vehicle ID's from year to year

- Only half of non-USPS vehicles from prior year carry identical vehicle ID

- Measure 6: \# of vehicles with invalid high fuel efficiencies

- Measure 7: year-to-year consistency of reporting

- b) \# of vehicles reported in current year but missing from prior year (40K)

- d) \# of vehicles reported in prior year inventory but missing from current year (28K)

- e) \# of vehicles with changes to "immutable" attributes (224K of $554 \mathrm{~K} ; 40.3 \%$ )

- Measure 8: \# of vehicles with placeholders for 1+ attributes - 20,400 vehicles with 28,500 placeholders

- Vehicles with invalid fuel type consumption 


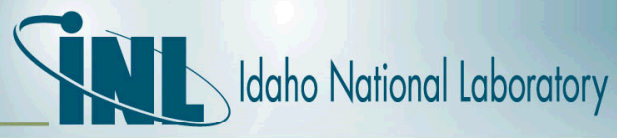

\section{New ways to look at fleet information...}

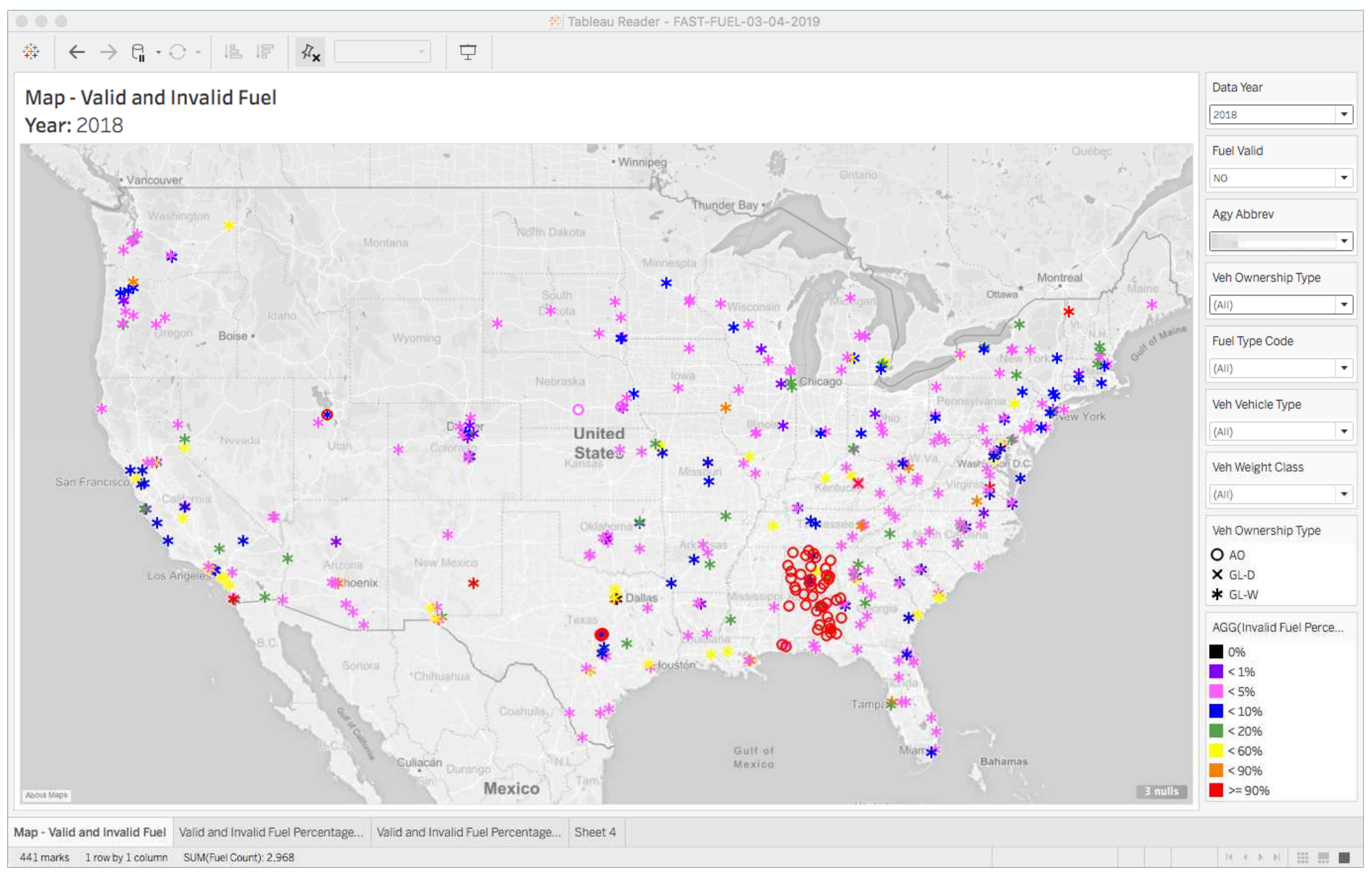




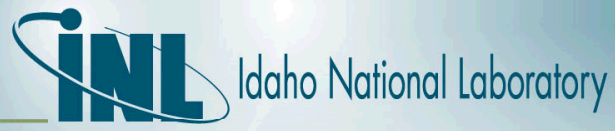

\section{New ways to look at fleet information...}

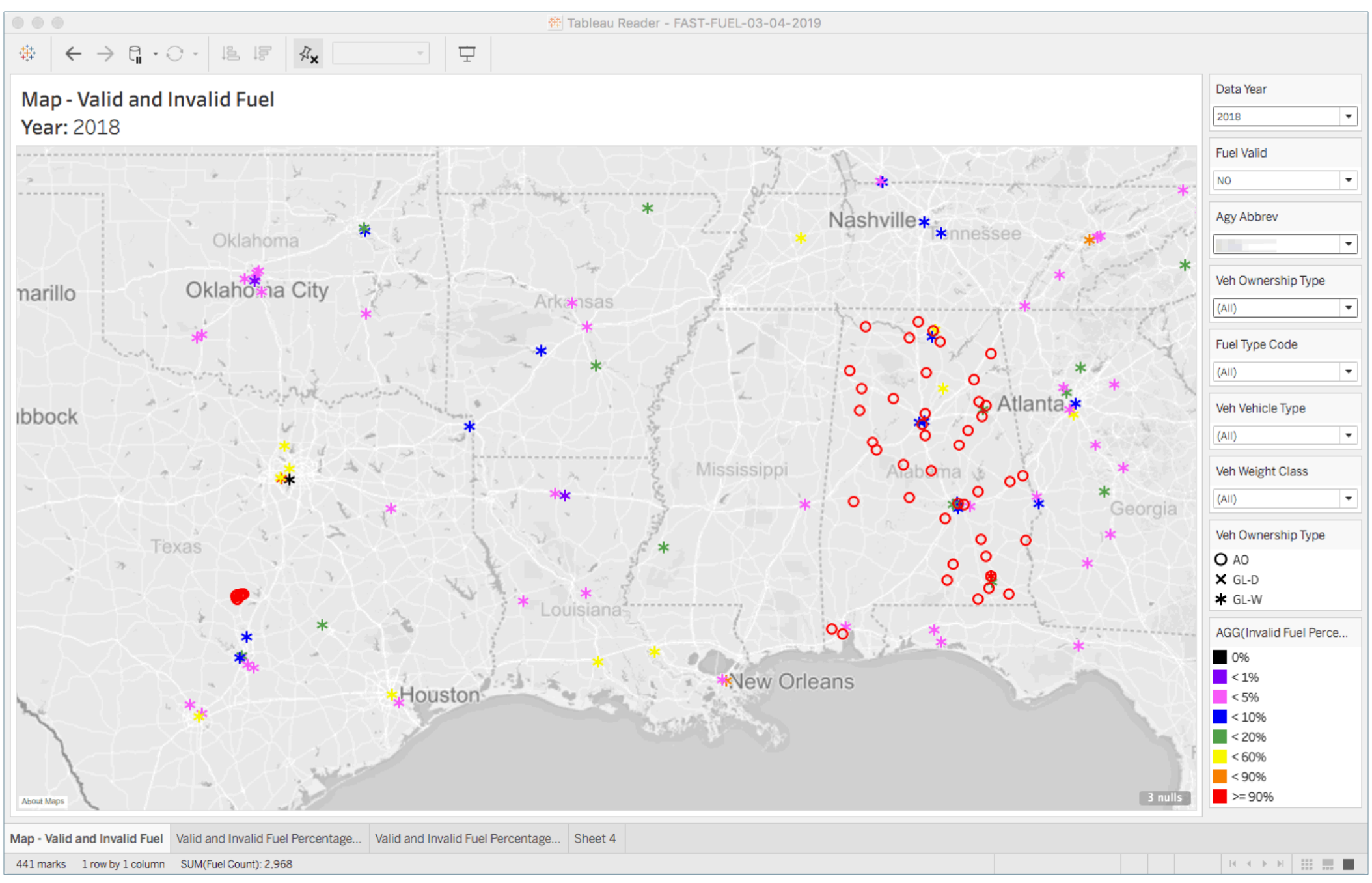




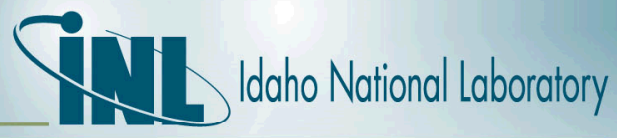

\section{New ways to look at fleet information...}

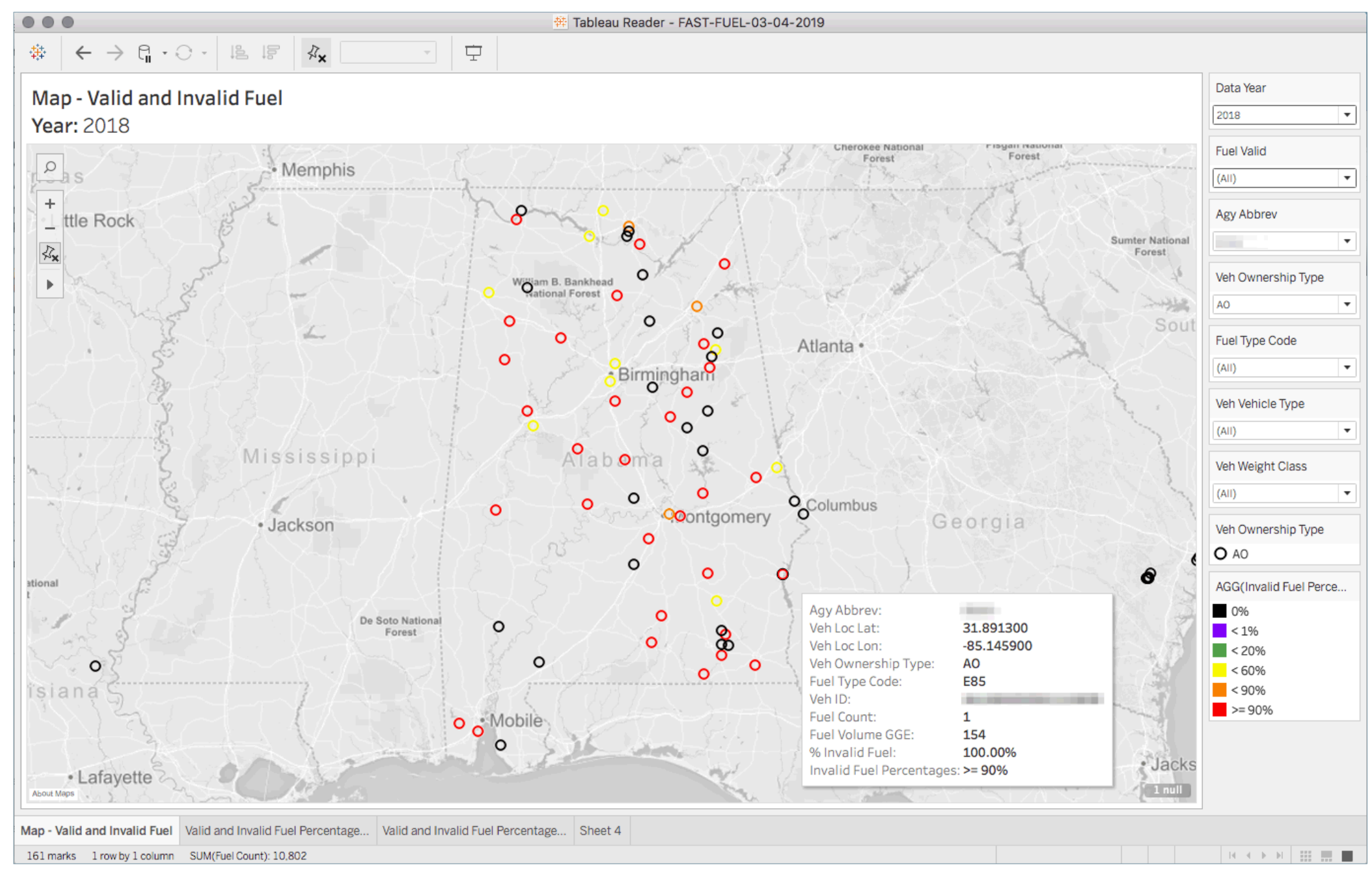




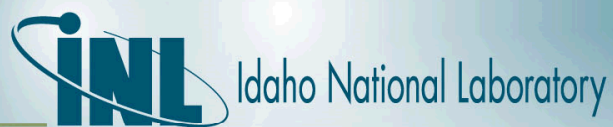

\section{Interested in more?}

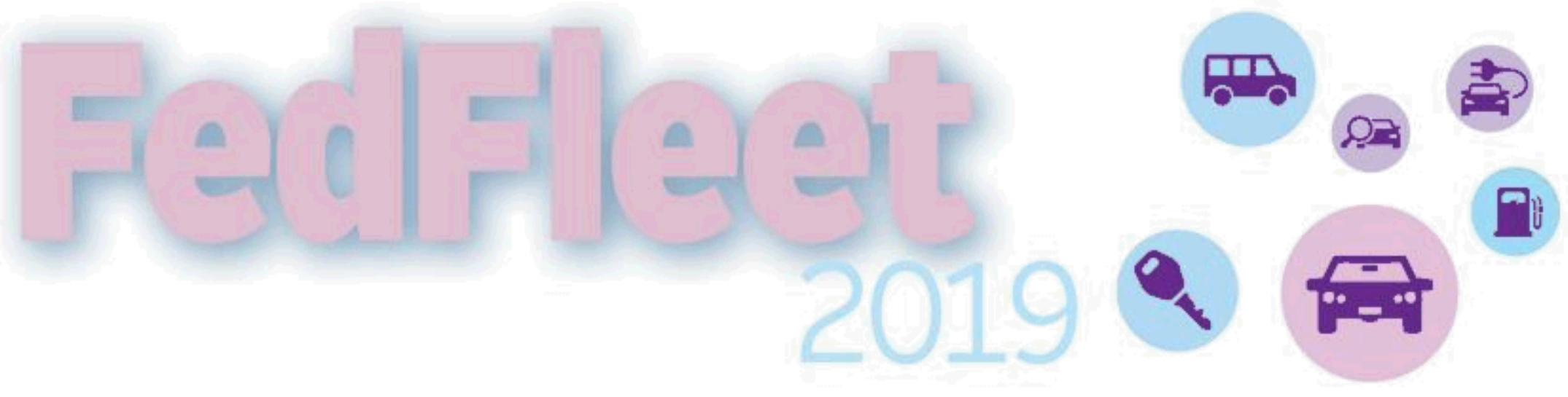

April 9-11, 2019 - Washington, DC 


\section{FAST Program Contact Information}

- DOE Federal Energy Management Program

- Brad Gustafson (brad.gustafson@ee.doe.gov)

- GSA Office of Government-wide Policy

- Jim Vogelsinger (james.vogelsinger@gsa.gov)

- Patrick McConnell (patrick.mcconnell@gsa.gov)

- EIA Office of Energy Consumption \& Efficiency Statistics

- Cynthia Sirk (cynthia.sirk@eia.gov)

- INL FAST Team

- Michelle Kirby (michelle.kirby@inl.gov)

- Ron Stewart (ron.stewart@inl.gov)

- Tim Raczek (tim.raczek@inl.gov)

- Twitter: @FASTdevs 